\title{
Kinetics of transesterification of Jatropha curcas-based triglycerides with an alcohol in the presence of alkaline catalyst
}

\begin{abstract}
The Jatropha curcas methyl ester can be produced through a transesterification reaction by using an alkaline catalyst with an alcohol as the excess reactant. The reaction was carried out in a batch mixed reactor under various operating condition. The kinetics study on the transesterification of Jatropha curcas-based triglycerides with methanol was carried out under various temperatures $(323,328,333$ and $338 \mathrm{~K})$. The conversion of triglycerides into methyl esters follows the first-order mechanism for the forward reaction. The reaction rate constants were determined and finally the rate constants were plotted against temperatures for calculating the activation energies. The values of kTG ranges from 0.11 to 0.17 and the values of $\mathrm{kDG}$ are from 0.07 to 0.20 respectively. The activation energies for stepwise reactions for transesterification of Jatropha curcas-based triglycerides and diglycerides with methanol are 27.38 and $46.72 \mathrm{~kJ}$ mol-1. Future work should examine the real step-wise reaction kinetics in Jatropha curcas biodiesel production under acid catalyst.
\end{abstract}

Keyword: Transesterification; Jatropha curcas triglycerides; Alkaline catalyst 